\title{
Decreased expression of fibroblast growth factor-4 and associated dysregulation of trophoblast differentiation in mouse blastocysts exposed to high D-glucose in vitro
}

\author{
A. Leunda-Casi, R. De Hertogh, S. Pampfer \\ Physiology of Human Reproduction Research Unit, Catholic University of Louvain Medical School, Brussels, Belgium
}

\begin{abstract}
Aims/hypothesis. Paracrine interactions are thought to operate between the inner cell mass and trophectoderm cell lineages to co-ordinate their expansion and differentiation during embryo implantation. We aimed to determine whether hyperglycaemia could interfere with this regulatory process.

Methods. Mouse blastocysts were pre-exposed to either control or high concentrations of D-glucose for $24 \mathrm{~h}$ in vitro and tested for their ability to attach and spread over a fibronectin-coated culture substrate. Quantitative immunocytochemistry was done on blastocysts to assess the protein expression of Fibroblast Growth Factor-4, a growth factor preferentially produced by the inner cell mass and thought to restrict trophectoderm differentiation into giant trophoblasts. Experiments were then done combining the pre-exposure to high D-glucose with the addition of recombinant fibroblast growth factor-4.
\end{abstract}

Results. Compared with control blastocysts, high Dglucose pre-treated embryos were found to form $18 \%$ larger trophoblast outgrowths. These blastocysts also showed a $30 \%$ reduction in the expression of fibroblast growth factor- 4 protein by inner cell mass cells as they were outgrowing. The trophoblast surface area per outgrowth and the trophoblast nuclear area were corrected when the addition of recombinant fibroblast growth factor-4 was combined with the pre-exposure to high D-glucose.

Conclusion/interpretation. The data suggests that trophectoderm differentiation is impaired by high D-glucose and that this effect is secondary to a deficiency in fibroblast growth factor-4 protein in the inner cell mass. These observations add a novel perspective to the study of the peri-implantation embryopathy associated with maternal diabetes. [Diabetologia (2001) 44: 1318-1325]

Keywords Glucose, blastocyst, FGF-4, ICM, TE, implantation, trophoblast.
Shortly before becoming involved in the process of implantation into the uterine wall, mammalian embryos reach the blastocyst stage. Two distinct cell lineages, the trophectoderm (TE) and the inner cell mass (ICM) are already present in these embryos.

Received: 2 February 2001 and in revised form: 8 June 2001

Corresponding author: R. De Hertogh, Physiology of Human Reproduction Research Unit (OBST 5330), University of Louvain Medical School, 53 Avenue Mounier, 1200 Brussels, Belgium, E-mail: dehertogh@obst.ucl.ac.be

Abbreviations: ICM, Inner cell mass; TE, trophectoderm; FGF-4, fibroblast growth factor-4; ECM, extra-cellular matrix
The peripheral TE consists of a single layer of epithelioid cells that differentiates into trophoblasts and contributes to the formation of the placenta. The ICM, in contrast, is an inner cluster of totipotent stem cells that continue to diversify into a variety of cell types to generate the different fetal tissues and organs during organogenesis. Studies have shown that ICM cells and TE cells have many different cellular, biochemical and molecular characteristics, including their susceptibility to embryotoxic agents [1].

Pre-conceptional maternal diabetes could already induce subtle cellular, biochemical and molecular damage in the embryos during the blastocyst period. These deficiencies are thought to predispose the em- 
bryos to various anomalies in their development after implantation [2-3]. Furthermore, some experiments have shown that ICM cells are more susceptible than TE cells to the direct cytotoxicity of hyperglycaemia [4-6]. Induction of apoptosis was found to occur predominantly in the ICM of rat blastocysts when exposed to hyperglycaemia in utero [4] or to high D-glucose in vitro [7], raising the hypothesis that an excess loss of crucial pre-fetal stem cells from the ICM lineage could be a key determinant of the early embryopathy associated with pre-conceptional diabetes [8].

Although little is known about the nature of the interactions between ICM and TE cells, evidence suggests that close cell contact is required between the two cell lineages to ensure the proper development of the implanting blastocyst [1]. Studies of ICM-TE interactions indicate that potent regulatory signals such as fibroblast growth factors (FGFs) could be produced by ICM cells and participate in the control of TE growth by paracrine or juxtacrine mechanisms [9]. The FGF-4 is thought to be one of these major candidate signals because this growth factor has been shown to be preferentially produced in the ICM cells of mouse blastocysts and to help maintain mouse TE cells in an undifferentiated state and proliferative mode $[10,11]$.

The observation that ICM cells are highly sensitive to the cytotoxicity of hyperglycaemia and the possible dependence on ICM-derived signals for normal TE development suggests that TE cells could be indirectly affected by a disruption in ICM-to-TE cell signalling. Previous experiments and our data suggest that TE cells and early trophoblasts of mouse and rat blastocysts display signs of abnormal growth following blastocyst exposure to hyperglycaemia [5, 12-14].

In our study, mouse blastocysts were exposed to different concentrations of D-glucose during $24 \mathrm{~h}$ and then analysed for their ability to attach and spread over a fibronectin-coated culture substrate. The expression of FGF-4 in the ICM of these embryos was estimated and the benefit of adding human recombinant FGF-4 to the high D-glucose treatment was also investigated.

\section{Materials and methods}

Embryo collection and culture. All investigations were done in accordance with the Guide for Care and Use of Laboratory Animals (National Academy of Science, 1996). Six-week-old female mice from the NMRI strain (University Animal House, Brussels, Belgium) were mated overnight with males from the $B_{6} \mathrm{D}_{2} \mathrm{~F}_{1}$ mouse strain (Iffa Credo, L'Arbresle, France). The presence of a vaginal plug was designated as day 1 of pregnancy. Early blastocysts were recovered on day 4 by flushing the uterine horns with pre-warmed Earle's Balanced Salt Solution (EBSS, Life Technologies, Parsley, UK) culture medium supplemented with $1 \mathrm{mmol} / \mathrm{l}$ glutamate, $1 \mathrm{mmol} / \mathrm{l}$ pyruvic acid,
$0.3 \%$ BSA, $100 \mathrm{U} / \mathrm{ml}$ penicillin and $100 \mu \mathrm{g} / \mathrm{ml}$ streptomycin. Blastocysts from different female mice were pooled before random assignment to different culture groups.

Pre-implantation analysis. Early blastocysts were cultured for $24 \mathrm{~h}$ in the EBSS-based culture medium with either $6 \mathrm{mmol} / \mathrm{l}$ or $28 \mathrm{mmol} / \mathrm{l} \mathrm{D}$-glucose. A combination of $22 \mathrm{mmol} / \mathrm{l} \mathrm{L}$-glucose and $6 \mathrm{mmol} / \mathrm{l} \mathrm{D}$-glucose served as control culture medium for the absence of hyperosmotic effect. At the end of the 24-h incubation period, the blastocysts were examined for different developmental parameters. During the culture period, the blastocoelic cavity of the early blastocyst expands and causes the zona pellucida to become thinner thus allowing the embryo to expand and ultimately hatch from this protective covering. Morphological distribution to either expanded blastocyst or more advanced hatched blastocyst was determined after observation on an inverted phase-contrast microscope. Blastocysts were analysed for the total number of cells per embryo [15]. Between 60 and 100 embryos were examined for each culture group in six independent experiments. Cells with signs of nuclear fragmentation (karyorhexis index) were also counted in the ICM and TE cell populations of around 30 blastocysts for each group in three independent experiments [16]. The three different groups of blastocysts were designated by the following abbreviations according to the composition of the culture medium in which they had been incubated: $6 \mathrm{mmol} / \mathrm{l}$, $28 \mathrm{mmol} / \mathrm{l}$ and $22+6 \mathrm{mmol} / \mathrm{l}$.

Peri-implantation analysis. Blastocysts were first incubated for $24 \mathrm{~h}$ in either $6 \mathrm{mmol} / 1,17 \mathrm{mmol} / \mathrm{l}, 28 \mathrm{mmol} / 1 \mathrm{D}$-glucose or in the hyperosmotic control culture medium and then transferred into fibronectin-coated culture wells (Bovine plasma fibronectin from Life Technologies, Parsley, UK). Fibronectin was chosen for the study of blastocyst outgrowth because it is a component of the basement membrane of the endometrium and interstitial matrix of the uterine stroma and also because increased fibronectin synthesis accompanies extra-cellular matrix $(\mathrm{ECM})$ remodelling within the uterine endometrium in preparation for implantation [17]. It has been shown to promote the attachment of mouse blastocysts and outgrowth of the trophoblast cells in vitro [18]. Several receptors of the integrin family are expressed by the mouse blastocyst which recognize a specific site of fibronectin and their interaction is supposed to mediate trophoblast cell migration [19]. Other ECM molecules (specially, laminin) are found in the endometrium and have been used as in vitro substrates for studies of blastocyst outgrowth. However, no differences were detected in vitro between laminin and fibronectin in their capacity to promote the attachment and spreading of the mouse blastocyst during this peri-implantation period [18].

In vitro incubation was then continued for another $48 \mathrm{~h}$ in CMRL 1066-based culture medium (Life Technologies, Parsley, UK) containing $6 \mathrm{mmol} / \mathrm{l} \mathrm{D}$-glucose, $10 \%$ fetal bovine se$\mathrm{rum}, 100 \mathrm{U} / \mathrm{ml}$ penicillin and $100 \mu \mathrm{g} / \mathrm{ml}$ streptomycin [20]. Under these culture conditions, blastocysts attach to the culture substrate and their TE cells start to transform into trophoblasts. Blastocyst spreading leads to the formation of a trophoblast outgrowth featuring a central ICM core surrounded by diploid trophoblasts and a fringe of peripheral giant trophoblasts. At the end of the second incubation period, the embryos were examined for their morphological distribution between unattached hatched blastocysts or trophoblast outgrowths. The surface of each trophoblast outgrowth was measured [14]. Between 30 and 50 blastocysts for each experimental group were examined in five independent experiments. The four different groups of embryos were designated by the following abbreviations according to the composition of the 
culture medium in which they had been incubated during the first 24-h incubation period: p-6 mmol/l, p- $17 \mathrm{mmol} / \mathrm{l}$, $\mathrm{p}-28 \mathrm{mmol} / \mathrm{l}$ and $\mathrm{p}-22+6 \mathrm{mmol} / \mathrm{l}$.

FGF-4 protein expression. Blastocysts were analysed by immunocytochemistry for the expression of FGF-4 at the end of the first incubation period in either $6 \mathrm{mmol} / \mathrm{l}$ or $28 \mathrm{mmol} / \mathrm{l} \mathrm{D}$-glucose or at the end of the second incubation period after being transferred into fibronectin-coated culture wells. Blastocysts observed at the end of the first incubation period were denuded from their zona pellucida by means of a short treatment in a Tyrode acid solution and then immobilized on concanavalin A-coated coverslips [21]. Adherent trophoblast outgrowths observed at the end of the second incubation period were directly processed for immunocytochemistry. Embryos were fixed with $1.7 \%$ paraformaldehyde in PBS for $30 \mathrm{~min}$ at $37^{\circ} \mathrm{C}$ and then permeabilized for $10 \mathrm{~min}$ in $1 \%$ Triton in PBS at room temperature. Incubation with a primary goat anti-human FGF-4 antibody (final concentration of $0.5 \mu \mathrm{g} / \mathrm{ml}$; Santa Cruz Biotechnology, Santa Cruz, Calif., USA) was done overnight at $4{ }^{\circ} \mathrm{C}$ in PBS supplemented with $1 \%$ Tween-20 (PBS-T) and $3 \%$ BSA. Embryos were washed in PBS-T and then exposed for $1 \mathrm{~h}$ at $37^{\circ} \mathrm{C}$ to a FITC-conjugated secondary rabbit antigoat $\mathrm{IgG}$ antibody (final concentration of $1.7 \mu \mathrm{g} / \mathrm{ml}$; Vector Laboratories, Burlingame, Calif., USA) in PBS-T and 3\% BSA. Embryos were finally counter-stained with $10 \mu \mathrm{mol} / \mathrm{l}$ TOPRO-3 iodide fluorochrome (Molecular Probes, Leiden, The Netherlands). Negative immunostaining control experiments included the substitution of the primary antibody with normal goat $\mathrm{IgG}$, its omission from the procedure or the omission of both primary and secondary antibodies (autofluorescence control) from the procedure. Immunostained embryos were observed using confocal laser scanning microscopy under a krypton and argon mixed gas laser fitted for the excitation of FITC $(488 \mathrm{~nm})$ and Texas Red $(568 \mathrm{~nm})$. The entire embryos were reconstituted by the projection of the serial sections acquired along the Z-axis. The FGF-4 protein expression in a blastocyst was measured from the intensity of the immunofluorescence staining in each digital section that had been acquired across the embryo. Measurement of FGF-4 immunostaining intensity was carried out in a similar way in trophoblast outgrowths except that the ICM core only of each embryo was assessed (FGF-4 expression is extremely low in trophoblast cells [22]). The FGF-4 protein contents were expressed in arbitrary intensity units for each blastocyst or for each ICM core and the results were corrected for variations in corresponding background staining and section areas. At least 10 embryos for each culture group were analysed in 3 independent experiments. The different groups of embryos were designated by the abbreviations $6 \mathrm{mmol} / \mathrm{l}$ and $28 \mathrm{mmol} / \mathrm{l}$ or $\mathrm{p}-6 \mathrm{mmol} / \mathrm{l}$, p$28 \mathrm{mmol} / \mathrm{l}$ and $\mathrm{p}-22+6 \mathrm{mmol} / \mathrm{l}$ according to the composition of the culture medium in which they had been incubated during the first incubation period.

Impact of recombinant FGF-4. Blastocysts were incubated in either $6 \mathrm{mmol} / \mathrm{l}$ or $28 \mathrm{mmol} / \mathrm{l} \mathrm{D}$-glucose in the presence or absence of $2.5 \mathrm{ng} / \mathrm{ml}$ human recombinant FGF-4 (R\&D Systems, Minneapolis, Minn., USA) in the presence of $1 \mu \mathrm{g} / \mathrm{ml}$ heparin for $24 \mathrm{~h}$. The embryos were then transferred into fibronectincoated culture wells and incubated for another $48 \mathrm{~h}$ with $6 \mathrm{mmol} / \mathrm{l} \mathrm{D-glucose}$ and no recombinant FGF-4. At the end of this second incubation period, the outgrowths were analysed for different developmental parameters. In addition to assessing their morphology and measuring their trophoblast outgrowth surface, embryos were also fixed and stained in $10 \mu \mathrm{mol} / 1$ TOPRO-3 iodide (Molecular Probes, Leiden, The Netherlands) for $15 \mathrm{~min}$ and then the number of trophoblasts detected around the central ICM core were counted. The average trophoblast nuclear area and the percentage of trophoblasts showing signs of karyorhexis were also measured in each embryo. Giant trophoblasts were identified on the basis of a previously published linear relation between trophoblast nuclear area and trophoblast nuclear DNA content [23]. Trophoblasts with a nuclear DNA content higher than $6 \mathrm{n}$ were counted as giant cells and their percentage (giant nucleus index) was determined in each trophoblast outgrowth. Between 12 and 22 embryos for each culture group were examined in three independent experiments. The different groups of embryos were designated by the abbreviations p- $6 \mathrm{~mol} / \mathrm{l}$, p$6 \mathrm{mmol} / \mathrm{l}+\mathrm{FGF}-4, \mathrm{p}-28 \mathrm{mmol} / \mathrm{l}$ and p-28 mmol/l + FGF-4 according to the composition of the culture medium in which they had been incubated during the first incubation period. Blastocysts were also incubated during the first incubation period in $22 \mathrm{mmol} / \mathrm{l} \mathrm{L}$-glucose $+6 \mathrm{mmol} / \mathrm{l} \mathrm{D}$-glucose containing culture medium $(\mathrm{p}-22+6 \mathrm{mmol} / \mathrm{l})$.

Statistical analysis. Morphological distributions were expressed as percentages and compared by Chi-square $\left(\chi^{2}\right)$ analysis. Average numbers of cells for each blastocyst and each trophoblast outgrowth, average trophoblast outgrowth surfaces and average trophoblast nuclear areas were given as Means \pm SEM values and compared by one-way analysis of variance coupled to post hoc Fisher's test. Percentages (indexes) of cells featuring signs of karyorhexis and percentages of trophoblasts transformed into giant cells were compared by means of nonparametric analysis Kruskal-Wallis. The FGF-4 protein expression data were tested for normal distribution and then compared using the Student's unpaired $t$ test in blastocysts cultured $24 \mathrm{~h}$ in $6 \mathrm{mmol} / \mathrm{l}$ and $28 \mathrm{mmol} / \mathrm{l} \mathrm{D}$-glucose. In trophoblast outgrowths pre-exposed to different combination of glucose, FGF-4 protein expression was compared by one-way analysis of variance coupled to post-hoc Fisher's test. A $p$ value of less than 0.05 was considered to be statistically significant.

\section{Results}

When mouse blastocysts were incubated for $24 \mathrm{~h}$ in either $6 \mathrm{mmol} / 1$ or $28 \mathrm{mmol} / \mathrm{l} \mathrm{D}$-glucose, no difference was found between the two culture groups with respect to the percentage of blastocysts that had hatched from the zona pellucida at the end of the incubation period ( $p=0.35$ ) (Fig. 1A). However, blastocysts exposed to $28 \mathrm{mmol} / \mathrm{l} \mathrm{D}$-glucose showed a decrease in the total number of cells for each embryo $(p \leq 0.05)$ (Fig.1B). Close examination of differentially stained blastocysts detected a $57 \%$ increase in the proportion of ICM cells showing signs of karyorhexis following exposure to $28 \mathrm{mmol} / \mathrm{l} \mathrm{D}$-glucose (Fig. 1C). However this increase was not statistically significant $(p=0.26)$. The incidence of this apoptotic nuclear event remained very low and did not changed in the TE cell lineage. None of the developmental markers analysed above were modified when blastocysts were cultured in a combination of $22 \mathrm{mmol} / \mathrm{l} \mathrm{L-glu-}$ cose and $6 \mathrm{mmol} / \mathrm{l} \mathrm{D}$-glucose.

In a second series of experiments, blastocysts preincubated $24 \mathrm{~h}$ in increasing concentrations of D-glucose and then further cultured $48 \mathrm{~h}$ in $6 \mathrm{mmol} / \mathrm{l} \mathrm{D}$-glu- 
A
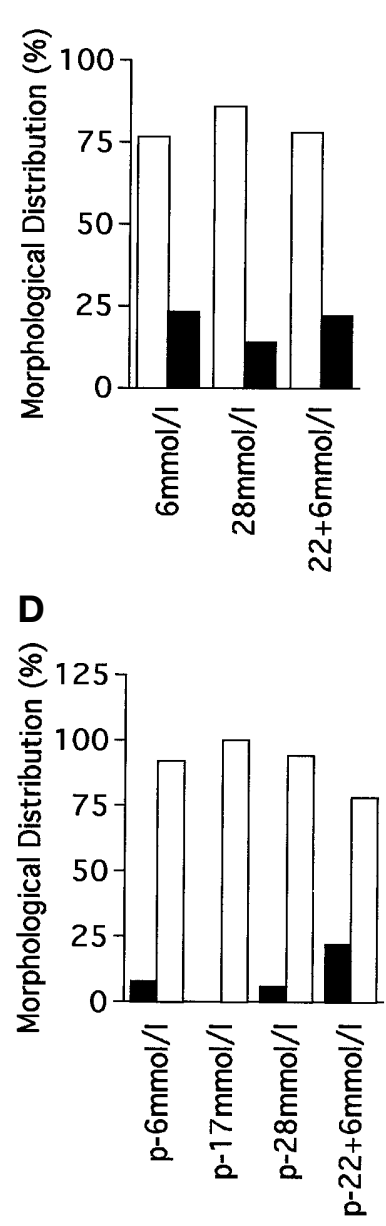

B

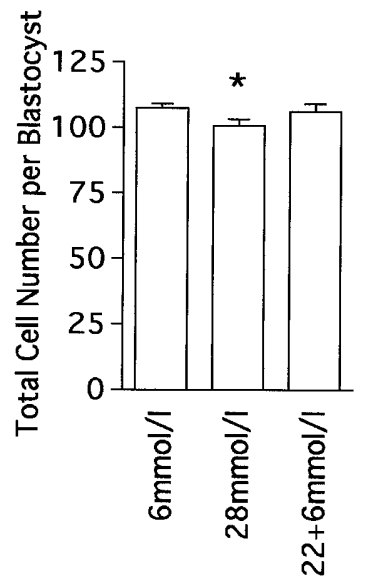

E

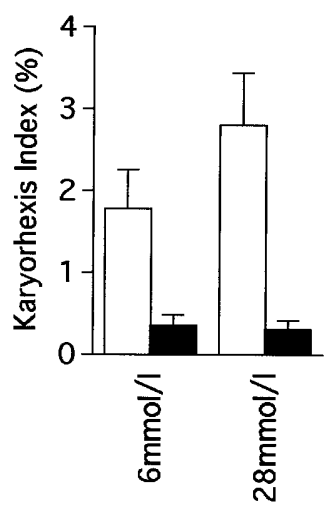

Incubation and pre-incubation ( $\mathrm{p}-$ ) glucose concentrations

Fig. 1 A-E. Influence of different concentrations of glucose on mouse blastocyst development. After 24 h of culture: A morphological distribution between expanded blastocysts $(\square)$ or hatched blastocysts $(\boldsymbol{\square}), \mathbf{B}$ total number of cells per blastocyst and $\mathbf{C}$ percentage of cells with signs of karyorhexis (nuclear fragmentation) in the ICM ( $\square)$ and TE ( $\square$ ) cell lineages. After $24 \mathrm{~h}$ of pre-incubation and a further $48 \mathrm{~h}$ of culture in $6 \mathrm{mmol} / \mathrm{l}$ D-glucose: D morphological distribution between hatched blastocysts ( $\square$ ) or trophoblast outgrowths ( $\square$ ) and $\mathbf{E}$ trophoblast outgrowth surface. ${ }^{*} p \leq 0.05$ vs the corresponding control value $(6 \mathrm{mmol} / \mathrm{l}$ or $\mathrm{p}-6 \mathrm{mmol} / \mathrm{l})$

cose, showed no significant difference with respect to the proportion of blastocysts that had attached and spread over the culture substrate $(p=0.07)$ (Fig.1D). Measurement of the total surface of the trophoblast outgrowths showed, however, that pretreating embryos with $17 \mathrm{mmol} / \mathrm{l}$ or $28 \mathrm{mmol} / \mathrm{l} \mathrm{D-glu-}$ cose resulted in a statistically significant $18 \%$ increase in the spreading of their trophoblasts $(p \leq 0.05)$ (Fig. 1E). When pre-treated with $17 \mathrm{mmol} /$ $1 \mathrm{D}$-glucose for $24 \mathrm{~h}$ before transfer into fibronectincoated culture wells, embryos from another female mouse strain $(O F 1)$ mated to $B_{6} \mathrm{D}_{2} \mathrm{~F}_{1}$ males showed a $27 \%$ increase in their trophoblast outgrowth surface compared with control embryos (data not shown). None of the developmental parameters analysed above were influenced by pre-exposing embryos to a combination of $22 \mathrm{mmol} / \mathrm{l} \mathrm{L}$-glucose and $6 \mathrm{mmol} / \mathrm{l}$ D-glucose during the first incubation period.

FGF-4 expression was observed in mouse blastocysts exposed to 6 or $28 \mathrm{mmol} / \mathrm{l} \mathrm{D}$-glucose for $24 \mathrm{~h}$ and after another $48 \mathrm{~h}$ in $6 \mathrm{mmol} / \mathrm{l} \mathrm{D}$-glucose when a trophoblast outgrowth was formed. In accordance with previous reports, FGF-4 immunostaining was detected predominantly in the ICM of hatched blastocysts and completely restricted to the ICM core after trophoblast outgrowth (Figs. 2A and D). Control immunocytochemical reactions showed the absence of non-specific staining when the primary anti-FGF4 antibody was either substituted with normal goat $\mathrm{IgG}$ or omitted from the protocol (data not shown). Autoimmunofluorescence was also not detectable (data not shown). Compared to control embryos, no difference in FGF-4 immunofluorescence intensity was detected when blastocysts were examined at the end of the 24-h incubation period in high D-glucose 

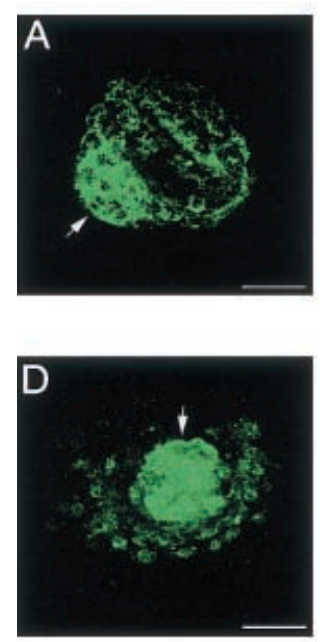
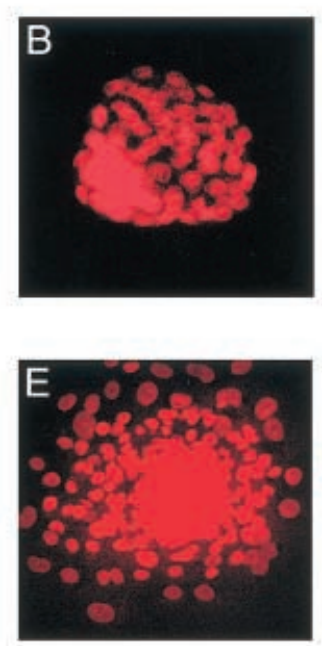

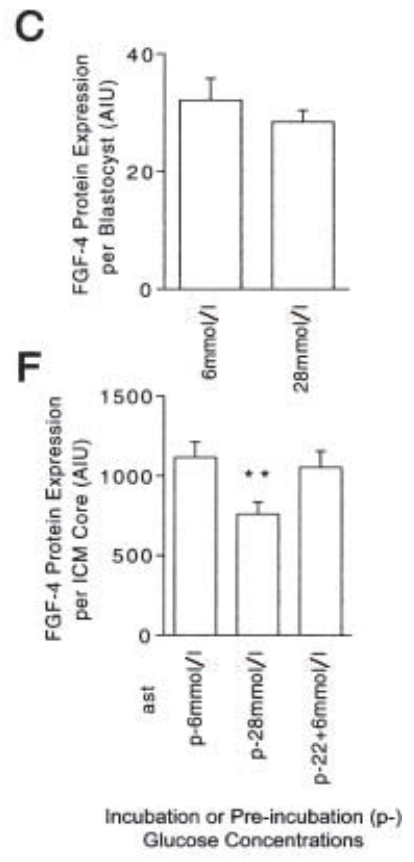

Fig. 2 A-F. Influence of different concentrations of glucose on FGF-4 protein expression. Immunolocalization of FGF-4 in an entire reconstituted blastocyst after $24 \mathrm{~h}$ in $6 \mathrm{mmol} / \mathrm{l} \mathrm{D-glu-}$ cose (A) or after outgrowth formation (D). Corresponding nuclear counter-stainings (B, E). Quantitative FGF-4 protein expression contents in whole blastocysts before $(\mathbf{C})$ or in the ICM core of embryos after (F) outgrowth formation. Data in (C) and (F) are expressed as arbitrary immunofluorescence intensity units (AIU). Scale bars represent $30 \mu \mathrm{m}$ in $(\mathbf{A}, \mathbf{B})$ and $60 \mu \mathrm{m}$ in $(\mathbf{D}, \mathbf{E})$. Arrows indicate the $\operatorname{ICM}$ core $(\mathbf{A}, \mathbf{D})$. $* * p \leq 0.01$ vs control value ( $\mathrm{p}-6 \mathrm{mmol} / \mathrm{l})$

$(p=0.35)$ (Fig. 2C). When embryos were observed after spreading over the fibronectin-coated culture substrate, the FGF-4 immunofluorescence intensity detected in the ICM of blastocysts pre-exposed to high D-glucose decreased by $32 \%(p \leq 0.01)$ (Fig. 2F). The FGF-4 protein expression in blastocysts pre-exposed to a combination of $22 \mathrm{mmol} / \mathrm{l}$ L-glucose and $6 \mathrm{mmol} / \mathrm{l} \mathrm{D}$-glucose during the first incubation period was similar to that found in control trophoblast outgrowths.

To further probe the possible cause and effect relationship between the decreased expression of FGF-4 in the ICM and the excess spreading of the trophoblast layer following exposure to high D-glucose, blastocysts were cultured in either $6 \mathrm{mmol} / \mathrm{l}$ or $28 \mathrm{mmol} / \mathrm{l}$ D-glucose in the presence or absence of $2.5 \mathrm{ng} / \mathrm{ml}$ of human recombinant FGF-4 for $24 \mathrm{~h}$ and then tested for their ability to spread over a fibronectin-coated culture surface. No difference was found between the four culture groups with respect to the percentage of blastocysts that were forming trophoblast outgrowths $(p=0.80)$ (Fig. 3A). In confirmation of previous data (Fig. 1E), pre-exposing blastocysts to high
D-glucose for $24 \mathrm{~h}$ resulted in a marked increase in the surface of their trophoblast outgrowth $(p \leq 0.05)$ (Fig.3B). Addition of recombinant FGF-4 during the high $\mathrm{D}$-glucose treatment period resulted in the normalization of this growth parameter. Trophoblast outgrowth spreading was not modified by the addition of recombinant FGF-4 to the control culture medium.

No difference was observed between the four culture groups with respect to the mean number of trophoblasts per outgrowth $(p=0.51)$ (Fig. 3C). Further examination, however, showed that the average nuclear area of the trophoblast cells increased by $27 \%$ in trophoblast outgrowths derived from blastocysts that had been pre-exposed to high D-glucose $(p \leq 0.01)$ (Fig. 3D). A higher proportion of trophoblasts were identified as giant cells at the periphery of these embryos $(p=0.09)$ (Fig. 3E). Both trophoblast outgrowth surface and trophoblast nuclear area values were corrected by the addition of recombinant FGF-4 to $28 \mathrm{mmol} / \mathrm{l}$ D-glucose during the 24 -h incubation period. Recombinant FGF-4 had no effect on these two parameters when added to the control culture medium. No difference was detected between the four culture groups with respect to the frequency of trophoblasts showing signs of karyorhexis $(p=0.32)$ (Fig. 3F). Other experiments showed that pre-exposure of blastocysts to a combination of $22 \mathrm{mmol} / \mathrm{l} \mathrm{L}$-glucose and $6 \mathrm{mmol} / \mathrm{l} \mathrm{D}$-glucose during the first incubation period had no influence on the different growth parameters tested above (number of trophoblasts per embryo, average nuclear area, index of giant cells and karyorhexis index, data not shown). 
A
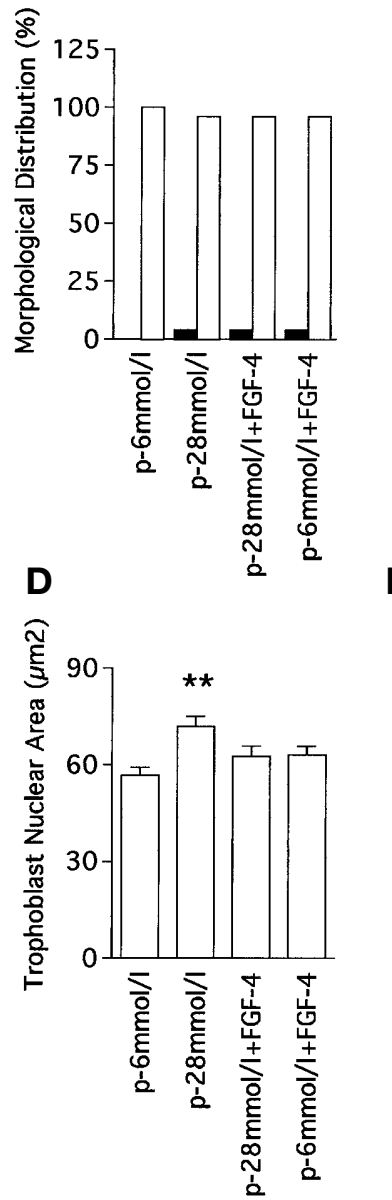

B
B C
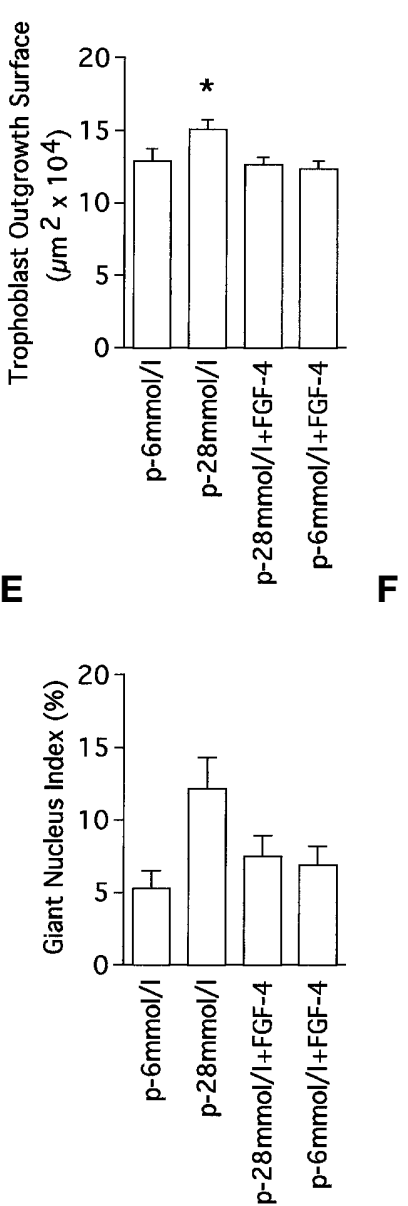
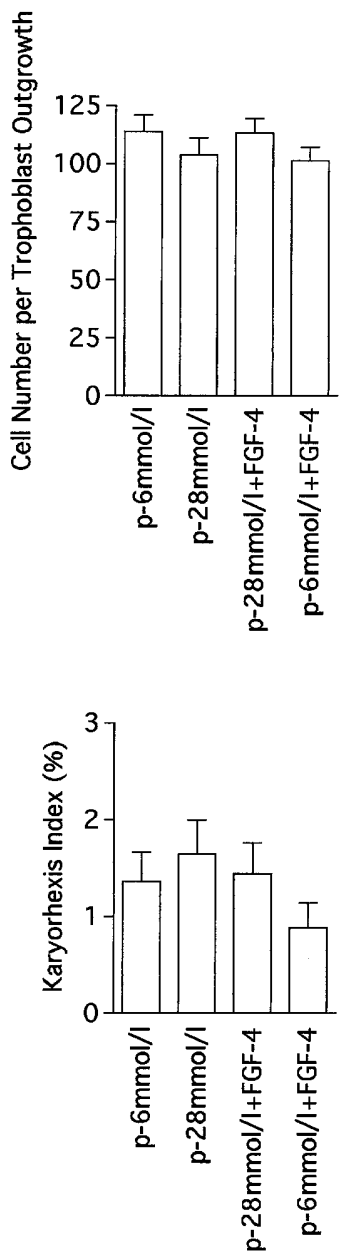

Pre-incubation glucose concentrations and FGF-4 conditions

Fig.3 A-F. Influence of FGF-4 $(2.5 \mathrm{ng} / \mathrm{ml})$ and different concentrations of D-glucose on trophoblast outgrowth. A Morphological distribution between hatched blastocysts $(\boldsymbol{\square})$ or trophoblast outgrowths $(\square)$. B Trophoblast outgrowth surface. C Number of cells per trophoblast outgrowth. D Trophoblast nuclear area. E Percentage of trophoblasts identified as giant cells. F Percentage of cells showing signs of nuclear fragmentation (karyorhexis index) per trophoblast outgrowth. $* p \leq 0.05$; $* * p \leq 0.01$ vs the corresponding control value ( $\mathrm{p}-6 \mathrm{mmol} / \mathrm{l})$

\section{Discussion}

Our data show that exposing mouse blastocysts to high D-glucose in vitro for a short time results in the formation of abnormally large trophoblast outgrowths. This alteration was associated with an increase in the average surface area of trophoblast nuclei, suggesting an increased proportion of trophoblasts presenting as giant cells. Thus, a disruption of the intra-embryonic mechanism that controls the transformation of the trophoblastic cells could be induced by high D-glucose.
Our findings correlate with previous reports showing that blastocysts collected from diabetic rats tended to form larger TE layers than was the case in control embryos [5] and contained a higher proportion of giant trophoblasts when allowed to spread onto a culture substrate [14]. Recent experiments have also shown that exposing mouse ectoplacental cone cells to high D-glucose stimulated these explants into excessive outgrowth [24]. In addition, abnormally high numbers of giant trophoblasts have been observed in utero-placental units of diabetic rats [25, R. Lea and S. Pampfer, unpublished data].

Not much is known about the cellular and molecular mechanism(s) responsible for controlling the development of trophoblast cells at the onset of implantation. Previous experiments suggest that important regulatory events operate at the interface between ICM cells and polar TE cells (those TE cells in direct contact with the ICM) to prevent a core group of these pre-trophoblastic cells from being transformed into giant cells [26, 27]. Maintenance of a sufficient population of diploid trophoblasts is necessary for full placental development beyond the first peri-im- 
plantation wave of giant cell transformation. Potent regulatory peptides such as those belonging to the FGF family are thought to be actively involved in the control of TE differentiation by ICM cells [9]. One of these factors, FGF-4, has been shown to be specifically expressed in the ICM cells of mouse blastocysts $[10,22,28]$, to stimulate the proliferation of mouse TE cells [29] and to repress their transformation and differentiation into giant trophoblasts [11]. In pre-implantation mouse blastocysts, the phagocytic activity of mural TE, a giant cell differentiation marker, was inhibited by the addition of FGF-4 [30]. Mouse embryos in which the $f g f-4$ gene was deleted could only form giant trophoblasts and aborted shortly after implantation [31]. Blastocysts, deficient for the transcription factor Oct-4, are characterized by very low expression levels of endogenous FGF-4 in their ICM and displayed an identical phenotype and could, furthermore, be rescued by the addition of exogenous FGF-4 [32].

Our experiments showed that, in contrast to control blastocysts, those embryos pre-incubated for $24 \mathrm{~h}$ in high concentrations of D-glucose contained less FGF-4 protein in the ICM cells after the blastocysts had been transferred for another $48 \mathrm{~h}$ into a second culture medium for in vitro implantation. Because the ICM core forms a very compact cell mass that makes the counting of these cells very difficult, it is not clear whether high D-glucose caused the reduction in FGF-4 by reducing the number of FGF-4producing cells or by impacting on the regulation of FGF-4 protein synthesis. Our data indicate the first possibility, however, because the percentage of ICM cells showing signs of apoptosis increased following exposure to high D-glucose. TE was more resistant to cell death, even after the second incubation period.

In our experiments, the addition of recombinant FGF-4 to high D-glucose prevented the subsequent formation of an abnormally large trophoblast outgrowth and normalized the mean nuclear area of the trophoblast cells. How exogenous FGF-4 corrects the influence of high D-glucose during the first incubation period is not known. The addition of FGF-4 could restore enough TE cells to a proliferative mode and delay their subsequent transformation. The absence of an effect of FGF-4 on control blastocysts is also intriguing. Unpublished experiments have shown that adding recombinant FGF-4 at the same concentration but during the second incubation period, significantly reduced trophoblast development (data not shown), confirming that there is a negative relationship between FGF-4 and giant cell transformation. Further work is clearly needed to understand how FGF-4 regulates trophoblast differentiation in both normal and pathological situations. What is known, however, is that FGF-4 requires the expression of a receptor by $\mathrm{TE}$ cells, probably FGFR2 [33, 34], and the combination with some still unknown factor(s) in the serum, to act properly [11, 30].

In conclusion, our data indicate that exposure to high D-glucose in vitro induces a decrease in the expression of FGF-4 protein in the ICM cell lineage of mouse blastocysts. The FGF-4 deficiency in turn disrupts the FGF-4-based negative regulatory effect that ICM cells exert over the differentiation of TE cells into giant trophoblasts. These observations could help explain some of the ultrastructural anomalies detected in the placenta of diabetic pregnancies.

Acknowledgements. This work was supported by a grant from the European Foundation for the Study of Diabetes (Fonds Suzanne et Jean Pirart), by an Action of Concerted Investigation from the General Direction of Research of the French Community in Belgium (Action de Recherche Concertée de la Direction Générale de la Recherche de la Communauté Française de Belgique) (grant number 96/01-96), by the Juvenile Diabetes Foundation International and by the Belgian Fund for Scientific Medical Research (Fonds de la Recherche Scientifique Médicale de Belgique) (grant number 3.4527.99). S.Pampfer is a research fellow with the National Fund for Scientific Research of Belgium (Fonds National de la Recherche Scientifique de Belgique). The authors would like to express their gratitude to I. Vanderheyden, J.F. Cornut, S. Cordi and P. Vandersmissen for their expert assistance and to Professor P. Courtoy for providing access to the confocal laser scanning microscope (grant 94531 94, FNRS).

\section{References}

1. Pampfer S (2000) Apoptosis in rodent peri-implantation embryos : differential susceptibility of inner cell mass and trophectoderm cell lineages. Placenta 21 [Suppl A]: 3-10

2. Moley KH (1999) Diabetes and pre-implantation events of embryogenesis. Semin Reprod Endocrinol 17: 137-151

3. Pampfer S (2000) Peri-implantation embryopathy induced by maternal diabetes. J Reprod Fertil [Suppl 55]: 129-139

4. De Hertogh R, Vanderheyden I, Robin D, Dufrasne E, Delcourt J (1991) Stimulatory and inhibitory effects of glucose and insulin on rat blastocysts development in vitro. Diabetes 40: 641-647

5. Lea RG, McCracken JE, McIntyre SS, Smith W, Baird JD (1996) Disturbed development of the pre-implantation embryo in the insulin-dependent diabetic BB/E rat. Diabetes 45: $1463-1470$

6. Pampfer S, Vanderheyden I, Michiels B, Vercheval M, De Hertogh R (1990) Decreased inner cell mass proportion in blastocysts from diabetic rats. Diabetes 39: 471-476

7. Pampfer S, Vanderheyden I, McCracken JE, Vesela J, De Hertogh R (1997) Increased cell death in rat blastocysts exposed to maternal diabetes in utero and to high D-glucose or tumor necrosis factor- $\alpha$ in vitro. Development 124: 4827-4836

8. Pampfer S, De Hertogh R (1996) Pre-implantation embryopathy associated with maternal diabetes. Diabetes Rev 4: 90-113

9. Rappolee DA, Werb Z (1994) The role of growth factors in mammalian pre-gastrulation development. Growth factors in early development, JAI Press, Greenwich, Conn

10. Rappolee DA, Basilico C, Patel Y, Werb Z (1994) Expression and function of FGF-4 in peri-implantation development in mouse embryos. Development 120: 2259-2269 
11. Tanaka S, Kunath T, Hadjantonakis AK, Nagy A, Rossant J (1998) Promotion of trophoblast stem cell proliferation by FGF-4. Science 282: 2072-2075

12. Wordinger RJ, Kell JA (1978) Elevated glucose levels influence in vitro hatching, attachment, trophoblast outgrowths and differentiation of the mouse blastocyst. Experientia 34: 881-882

13. Zusman I, Ornoy A, Yaffe P, Shafrir E (1985) Effects of glucose and serum from streptozotocin-diabetic and nondiabetic rats on the in vitro development of pre-implantation mouse embryos. Isr J Med Sci 21: 359-365

14. Pampfer S, Wuu YD, Vanderheyden I, De Hertogh R (1994) In vitro study of the carry-over effect associated with early diabetic embryopathy in the rat. Diabetologia 37: $855-862$

15. Tarkowski RK (1966) An air-drying method for chromosome preparations from mouse eggs. Cytogenetics 5: 394-400

16. Pampfer S, Wuu YD, Vanderheyden I, De Hertogh R (1994) Expression of tumor necrosis factor- $\alpha$ receptors and selective effect of TNF- $\alpha$ on the inner cell mass in mouse blastocyst. Endocrinology 134: 206-212

17. Rider V, Carlone DL, Witrock D, Cai C, Oliver N (1992) Uterine fibronectin mRNA content and localization are modulated during implantation. Dev Dyn 195: 1-14

18. Armant DR, Kaplan HA, Lennarz WJ (1986) Fibronectin and laminin promote in vitro attachment and outgrowth of mouse blastocysts. Dev Biol 116: 519-523

19. Yelian FD, Yang Y, Hirata JD, Schultz JF, Armant DR (1995) Molecular interactions between fibronectin and integrins during mouse blastocyst outgrowth. Mol Reprod Dev 41: 435-448

20. Wuu YD, Pampfer S, Vanderheyden I, Lee KH, De Hertogh R (1999) Tumor necrosis factor- $\alpha$ decreases the viability of mouse blastocysts in vitro and in vivo. Biol Reprod 60: 479-483

21. Maro B, Johnson MH, Pickering SJ, Flach G (1984) Changes in actin distribution during fertilization of the mouse egg. J Embryol Exp Morphol 81: 211-237

22. Brison DR, Schultz RM (1996) RT-PCR- based method to localize the spatial expression of genes in the mouse blastocyst. Mol Reprod Dev 44: 171-178
23. Barlow PW, Sherman MI (1972) The biochemistry of differentiation of mouse trophoblasts: studies on polyploidy. J Embryol Exp Morphol 27: 447-465

24. Caluwaerts S, Pijnenborg R, Luyten C, Van Assche FA (2000) Growth characteristics of diabetic rat ectoplacental cones in vivo and in vitro. Diabetologia 43: 939-945

25. Padmanabhan R, Al-Zuhair AG (1990) Ultrastructural studies on the placenta of streptozotocin-induced maternal diabetes in the rat. Z Mikrush Anat Forsch 104: 212-230

26. Gardner RL, Johnson MH (1972) An investigation of inner cell mass and trophoblast tissues following their isolation from the mouse blastocyst. J Embryol Exp Morphol 28: 279-312

27. Gardner RL, Beddington RSP (1988) Multi-lineage "stem" cells in the mammalian embryo. J Cell Sci [Suppl 10]: 11-27

28. Niswander L, Martin GR (1992) FGF-4 expression during gastrulation, myogenesis, limb and tooth development in the mouse. Development 114: 755-768

29. Chai N, Patel Y, Jacobson K, McMahon A, Rappolee DA (1998) FGF is an essential regulator of the fifth cell division in pre-implantation mouse embryo. Dev Biol 198: 105-115

30. Rassoulzadegan M, Rosen B, Gillot I, Cuzin F (2000) Phagocytosis reveals a reversible differentiated state early in the development of the mouse embryo. EMBO J 19: 3295-3303

31. Feldman B, Poueymirou W, Papaioannou VE, DeChiara TM, Goldfarb M (1995) Requirement of FGF-4 for postimplantation mouse development. Science 267: 246-249

32. Nichols J, Zevnik B, Anastassiadis K et al. (1998) Formation of pluripotent stem cells in the mammalian embryo depends on the POU transcription factor Oct-4. Cell 95: 379-391

33. Arman E, Haffner-Krausz R, Chen Y, Heath JK, Lonai P (1998) Targeted disruption of fibroblast growth factor (FGF) receptor-2 suggests a role for FGF signaling in pregastrulation mammalian development. Proc Natl Acad Sci USA 95: 5082-5087

34. Haffner-Krausz R, Gorivodsky M, Chen Y, Lonai P (1999) Expression of FGF-R2 in the early mouse embryo indicates its involvement in pre-implantation development. Mech Dev 85: 167-172 